\title{
A Triad Photoanode for Visible Light-Driven Water Oxidation via Immobilization of Molecular Polyoxometalate on Polymeric Carbon Nitride
}

Ruihao Gong, ${ }^{a}$ Dariusz Mitoraj, ${ }^{\mathrm{b}}$ Dandan Gao, ${ }^{\mathrm{a}}$ Manuel Mundszinger, ${ }^{\mathrm{c}}$ Dieter Sorsche, ${ }^{\mathrm{a}}$ Ute Kaiser, ${ }^{\mathrm{c}}$ Carsten Streb, ${ }^{\mathrm{a}}$ Radim Beranek, ${ }^{*, \mathrm{~b}}$ Sven Rau*,a

\footnotetext{
${ }^{a}$ Institute of Inorganic Chemistry I, Ulm University, Albert-Einstein-Allee 11, 89081 Ulm, Germany

${ }^{\mathrm{b}}$ Institute of Electrochemistry, Ulm University, Albert-Einstein-Allee 47, $89081 \mathrm{Ulm}$, Germany

'Electron Microscopy Group of Materials Science, Ulm University, Albert-Einstein-Allee 11, 89081 Ulm, Germany

*Corresponding authors: radim.beranek@uni-ulm.de, sven.rau@uni-ulm.de
}

\begin{abstract}
Due to their availability, low cost, non-toxicity and tunability, polymeric carbon nitrides $\left(\mathrm{CN}_{\mathrm{x}}\right)$ represent one of the most attractive materials classes for the development of fully sustainable photo(electro)catalytic systems for solar-driven water splitting. However, the development of $\mathrm{CN}_{\mathrm{x}}$-based photoanodes for visible light-driven water oxidation to dioxygen is rather challenging, particularly due to issues related to photoelectrode stability and effective coupling of the light absorber with water oxidation catalysts. Herein, a triadic photoanode comprising a porous $\mathrm{TiO}_{2}$ electron collector scaffold sensitized by $\mathrm{CN}_{\mathrm{x}}$ coupled to a molecular cobalt polyoxometalate $\left(\mathrm{CoPOM}=\left[\mathrm{CO}_{4}\left(\mathrm{H}_{2} \mathrm{O}\right)_{2}\left(\mathrm{PW}_{9} \mathrm{O}_{34}\right)_{2}\right]^{10-}\right)$ catalyst is reported. Complete water oxidation to dioxygen under visible $(\lambda>420 \mathrm{~nm})$ light irradiation is demonstrated, with photocurrents down to relatively low bias potentials $(0.2 \mathrm{~V}$ vs. RHE). Furthermore, polyethyleneimine (PEI), a cationic polymer is shown to act as an effective and non-sacrificial electrostatic linker for immobilization of the anionic CoPOM onto the negatively charged surface of $\mathrm{CN}_{\mathrm{x}}$. The optimized deposition of CoPOM using the PEI linker translates directly into improved efficiency of the transfer of photogenerated holes to water molecules and to enhanced oxygen evolution. This work thus provides important design rules for effective immobilization of POM-based catalysts into soft-matter photoelectrocatalytic architectures for light-driven water oxidation.
\end{abstract}

Keywords: Water splitting, Oxygen evolution, Photoelectrochemistry, Carbon nitride, Polyoxometalates 


\section{Introduction}

Solar-driven water splitting utilizing photo(electro)catalytic systems is a possible strategy to secure the future supply of low-entropy energy in form of storable high-energy molecular fuels, such as hydrogen, alcohols or hydrocarbons. ${ }^{[1-5]}$ However, practically viable and sustainable systems required for large-scale applications should be preferably based on highly abundant and low-cost materials with non-critical availability, i.e., without any possible supply restrictions due to various political, economic or environmental concerns. In terms of sustainability, low cost and non-toxicity, one of the most attractive materials for photo(electro)catalytic applications are polymeric carbon nitrides $\left(\mathrm{CN}_{\mathrm{x}}\right)^{[6,7]}$ Carbon nitrides are readily available, tunable and chemically robust polymers, ${ }^{[8]}$ that have been widely utilized in a variety of light-driven chemical processes such as hydrogen evolution, ${ }^{\left[{ }^{9-12]}\right.} \mathrm{CO}_{2}$ reduction, ${ }^{[13,14]}$ selective chemical syntheses, ${ }^{[15-18]}$ or organic pollutants degradation. ${ }^{[19,20]}$ However, the studies demonstrating visible light-driven water oxidation to dioxygen using $\mathrm{CN}_{\mathrm{x}}$-based photoelectrocatalytic systems are still rather rare. ${ }^{[21,22]}$ This is, on the one hand, due to the notoriously slow kinetics of the oxygen evolution reaction (OER), ${ }^{[23]}$ which typically results in accumulation of oxidizing equivalents that translates in enhanced photocorrosion of $\mathrm{CN}_{\mathrm{x} .}{ }^{[24]}$ On the other hand, the very fabrication of mechanically robust $\mathrm{CN}_{\mathrm{x}}$-based photoelectrodes is challenging, ${ }^{[25,26]}$ in particular due to the poor adhesion of $\mathrm{CN}_{\mathrm{x}}$ to conductive substrates, ${ }^{[27-30]}$ and the very low conductivity of $\mathrm{CN}_{\mathrm{x}}$ films, hindering efficient charge transport to the external circuit. ${ }^{[31]}$

In our own work, we have been developing a distinct type of hybrid $\mathrm{CN}_{\mathrm{x}}$-based photoanodes in which a thin layer of $\mathrm{CN}_{\mathrm{x}}$ is deposited onto a porous $\mathrm{TiO}_{2}$ layer that acts as an electron-collecting scaffold, overcoming thus at the same time both the problems of low adhesion and low electronic conductivity of $\mathrm{CN}_{\mathrm{x}}$. Such photoanodes are capable of visible light-driven oxygen evolution upon deposition of a suitable cocatalyst for water oxidation, typically in form of metal oxide ( $\left(\mathrm{rO}_{\mathrm{x}}, \mathrm{CoO}_{\mathrm{x}}, \mathrm{NiO}_{\mathrm{x}}\right)$ nanoparticles. ${ }^{[24,32-39]}$ Notably, we found out that one of the crucial problems of the metal oxide nanoparticles as cocatalysts is their parasitic absorption of visible light, blocking thus the light absorption by the light absorber. This problem could be only partially overcome by using, for example, ultrasmall $(1-2 \mathrm{~nm}) \mathrm{CoO}(\mathrm{OH})_{\times}$nanoparticles that exhibit a larger bandgap and correspondingly better transparency in the visible range due to quantum size effects. ${ }^{[24]}$ This led us to hypothesize that, in contrast to conventional bulk metal oxide-based water oxidation catalysts, a molecular-scale catalyst might be favorable for preventing the undesired light absorption by the catalyst and enabling also more controllable cocatalyst deposition. With this motivation in mind, we turned our attention to water oxidation catalysts based on well-defined molecular polyoxometalates (POMs), such as $\left[\mathrm{CO}_{4}\left(\mathrm{H}_{2} \mathrm{O}\right)_{2}\left(\mathrm{PW}_{9} \mathrm{O}_{34}\right)_{2}\right]^{10-}=\mathrm{CoPOM}$, a tetra-cobalt-doped polyoxometalate, that have attracted much attention with regards to catalytic applications, ${ }^{[40-44]}$ and have been previously utilized as cocatalysts 
on various semiconducting metal oxides (e.g., $\mathrm{TiO}_{2}, \mathrm{Fe}_{2} \mathrm{O}_{3}$ ) to fabricate photoanodes for light-driven water splitting. ${ }^{[45,46]}$ However, to the best of our knowledge, no studies on $\mathrm{CN}_{x}$-based photoanodes comprising molecular POMs cocatalysts for photoelectrocatalytic water-splitting have been reported so far.

Herein, we report for the first time a triadic design of a photoanode consisting of porous $\mathrm{TiO}_{2}$ as an electron collector, $\mathrm{CN}_{\mathrm{x}}$ as a sensitizer for visible light, and CoPOM as a molecular water oxidation catalyst. The triad photoanode enables visible $(\lambda>420 \mathrm{~nm})$ light-driven oxidation of water to dioxygen at moderate bias potentials ( $>0.2 \mathrm{~V}$ vs. RHE). Notably, we show that effective immobilization of CoPOM into the porous structure of the photoanode plays a crucial role in photoanode performance and can be significantly improved using polyethyleneimine (PEI), a cationic polymer that can act as a non-sacrificial, electrostatic linker between the surface of $\mathrm{CN}_{\mathrm{x}}$ and the COPOM that are both charged negatively (Scheme 1). The thus achieved optimized immobilization of CoPOM is demonstrated to result in a more efficient transfer of photogenerated holes to water molecules and enhanced oxygen evolution.

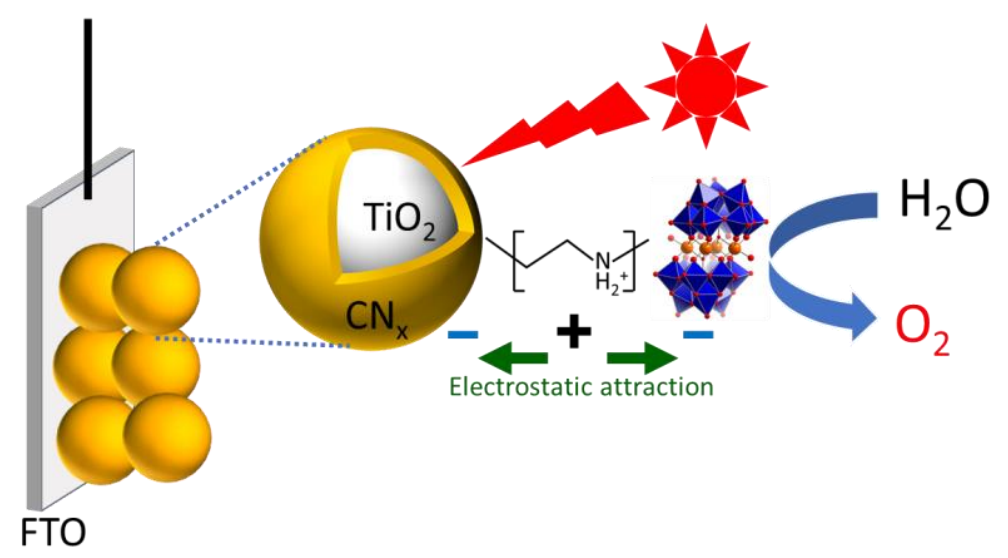

Scheme 1: The fabrication of the $\mathrm{CN}_{\mathrm{x}} / \mathrm{TiO}_{2}$ hybrid photoanode with an anionic molecular CoPOM cocatalyst immobilized via electrostatic attraction on the negatively charged $\mathrm{CN}_{\mathrm{x}}$ surface using a positively charged cationic PEI linking agent.

\section{Experimental Section}

Materials: Fluorine-doped tin oxide (FTO) Pilkington TEC glass was purchased from XOP company (XOP Glass, Castellón Spain). Deionized water was used for rinsing samples. $\mathrm{TiO}_{2}$ powder (Hombikat UV 100, Sachtleben, Germany, anatase, specific surface area (BET) $300 \mathrm{~m}^{2} / \mathrm{g}$, crystallite size $<10 \mathrm{~nm}$ ) was used to prepare the substrate for $\mathrm{CN}_{\mathrm{x}}$ deposition. Urea, polyethyleneimine (50 wt\%, dissolved in water), anhydrous ethanol, 2-propanol, acetone, sodium hydroxide, boric acid (99.5\%), sodium sulfite, 
and hydrochloric acid (37\%) were purchased from Sigma-Aldrich, $\mathrm{NaWO}_{4} \cdot 2 \mathrm{H}_{2} \mathrm{O}, \mathrm{Na}_{2} \mathrm{HPO}_{4}, \mathrm{NaCl}$ and $\mathrm{Co}\left(\mathrm{NO}_{3}\right)_{2} \cdot 6 \mathrm{H}_{2} \mathrm{O}$ were provided by Merck.

Synthesis of CoPOM: The CoPOM complex was synthesized according to literature. ${ }^{[40]}$ Briefly, $\mathrm{Na}_{2} \mathrm{WO}_{4} \cdot 2 \mathrm{H}_{2} \mathrm{O}(50.89 \mathrm{~g}), \mathrm{NaHPO}_{4} \cdot 7 \mathrm{H}_{2} \mathrm{O}(4.60 \mathrm{~g})$ and $\mathrm{Co}\left(\mathrm{NO}_{3}\right)_{2} \cdot 6 \mathrm{H}_{2} \mathrm{O}(9.98 \mathrm{~g})$ were dissolved in $50 \mathrm{~mL}$ deionized water in a $200 \mathrm{~mL}$ round-bottom flask. The $\mathrm{pH}$ was adjusted to 7 by $\mathrm{HCl}$ under magnetic stirring. The solution was then stirred and refluxed at $100{ }^{\circ} \mathrm{C}$ for $2 \mathrm{~h}$ and cooled down to room temperature. CoPOM was finally obtained by recrystallization and washed by deionized water. The purity of CoPOM is confirmed by Attenuated total reflection Fourier transform infrared (ATR-IR) spectroscopy.

Preparation of $\mathrm{FTO} / \mathrm{TiO}_{2}$ substrates: $\mathrm{TiO}_{2}$ layers on $\mathrm{FTO}$ were prepared using an established doctorblading protocol. ${ }^{[24]}$ Briefly, $0.25 \mathrm{~g} \mathrm{TiO}_{2}$ powder (Hombikat UV-100, pure anatase) was added to 1.25 $\mathrm{mL}$ anhydrous ethanol. The mixture was treated in ultrasonic bath for $10 \mathrm{~min}$ to produce a welldispersed suspension. The FTO glass substrates with a size of $1.5 \times 2.5 \mathrm{~cm}$ were first cleaned by acetone for removing residual organic contaminants by ultrasonication for $20 \mathrm{~min}$. The cleaned FTO glass was then etched in $0.1 \mathrm{M} \mathrm{NaOH}$ and rinsed with deionized water. Two FTO glass pieces were placed between microscope glasses and fixed using a $3 \mathrm{M}$ scotch tape as frame and spacer, leaving an exposed area of $\sim 1.5 \mathrm{~cm} \times 1.5 \mathrm{~cm}$. Then, $200 \mu \mathrm{LTiO}_{2}$ suspension was dropped on the microscope glass and gently swept by a glass stick onto the FTO glass pieces. After drying at $70{ }^{\circ} \mathrm{C}$ for $20 \mathrm{~min}$, the $\mathrm{TiO}_{2}$ films were pressed at $10^{4} \mathrm{~N}$ to improve the mechanical stability. All samples were calcined at $450{ }^{\circ} \mathrm{C}$ for $30 \mathrm{~min}$ in air before any tests or further treatments. The $\mathrm{FTO} / \mathrm{TiO}_{2}$ substrates are abbreviated as $\mathrm{TiO}_{2}$ in this report.

Deposition of $\mathrm{CN}_{\mathrm{x}}: \mathrm{CN}_{\mathrm{x}}$ was deposited by chemical vapor deposition of urea pyrolysis products according to our previous report. ${ }^{[24]}$ Two pieces of $\mathrm{TiO}_{2}$ electrodes were placed in a Schlenk tube connected to a round-bottom flask containing $1 \mathrm{~g}$ of urea. Before the $\mathrm{CN}_{\mathrm{x}}$ deposition was started, the muffle oven (Carbolite, Germany) was preheated to $425^{\circ} \mathrm{C}$. Then, the reactor was directly placed into the muffle oven and heated at $425{ }^{\circ} \mathrm{C}$ for $30 \mathrm{~min}$. Finally, the reactor was cooled down to room temperature in air. The resulting electrodes are denoted as $\mathrm{CN}_{x}-\mathrm{TiO}_{2}$.

Immobilization of CoPOM on $\mathrm{CN}_{\mathbf{x}}-\mathrm{TiO}_{2}$ : First, COPOM ( $5 \mathrm{mM}$ ) and PEI (6 mM, based on monomer) solutions in an aqueous solution of sodium phosphate $(80 \mathrm{mM}, \mathrm{pH}=5)$ and $\mathrm{NaCl}(137 \mathrm{mM})$ were prepared. Then, $\mathrm{CN}_{\mathrm{x}}-\mathrm{TiO}_{2}$ electrode was firstly dipped into the $\mathrm{PEI}$ solution for $5 \mathrm{~min}$, then rinsed with distilled water and dried in air, followed by dipping in the CoPOM solution for another $5 \mathrm{~min}$. The dipping processes in $\mathrm{PEI}$ and COPOM were alternately repeated for 5 times to acquire desired amount of COPOM and the sample was named as COPOM-PEI-CN $-\mathrm{TiO}_{2}$. The reference sample without PEI was 
prepared by dipping $\mathrm{CN}_{\mathrm{x}}-\mathrm{TiO}_{2}$ only into the CoPOM solution for 5 times and named as CoPOM-CN $\mathrm{N}^{-}$ $\mathrm{TiO}_{2}$

Material characterization: The electronic absorption spectra were measured using a UV-Vis spectrophotometer (UV-2600, Shimadzu, Japan) equipped with the integrating sphere and the absorptance (Abs.) was calculated by the equation:

$$
\text { Absorptance }(\%)=100 \%-\text { Reflectance }(\%)-\text { Transmittance }(\%)
$$

The baselines were recorded using an $\mathrm{FTO}$ glass and a $\mathrm{BaSO}_{4}$ plate as references for transmittance and reflectance, respectively. Scanning Electron Microscopy (SEM) and Energy-dispersive X-ray spectroscopy (EDX) elemental mapping were performed using an NVision 40 (Zeiss Microscopy, Germany) scanning electron microscope equipped with an Octane Elite (EDAX, USA) EDX system. Photoluminescence (PL) spectra were recorded on an RF-6000 spectrofluorophotometer (Shimadzu, Japan) using excitation wavelength of $360 \mathrm{~nm}$ with a $400 \mathrm{~nm}$ cut-off filter placed in front of the emission detector. Attenuated total reflection Fourier transform infrared (ATR-IR) spectroscopy was performed by the FT-IR spectrometer (Alpha II, Bruker, Germany). X-ray photoelectron spectroscopy (XPS) measurements were performed with monochromatized Al Ka radiation using a PHI Quantera SXM system (ULVAC-PHI, Japan). The binding energies were calibrated based on $C$ is peak of adventitious carbon $(284.8 \mathrm{eV})$.

Photoelectrocatalytic measurements: The photoelectrochemical measurements were conducted using a SP-300 BioLogic potentiostat and a typical 3-electrode system consisting of a Pt wire counter electrode, a $\mathrm{Ag} / \mathrm{AgCl}(3.5 \mathrm{M} \mathrm{KCl}, 0.207 \mathrm{~V}$ vs. SHE) reference electrode and tested photoanodes as working electrodes with geometric irradiation area of $0.5 \mathrm{~cm}^{2}$. Photoanodes were irradiated by visible light $(\lambda>420 \mathrm{~nm})$ using a $150 \mathrm{~W}$ Xe lamp (L.O.T.-Oriel) with light power density of $\sim 150 \mathrm{~mW} \mathrm{~cm}^{-2}$, equipped with a KG-3 (LOT-Quantum Design) heat-absorbing filter and a $420 \mathrm{~nm}$ longpass optical filter. All electrodes were illuminated from backside (through FTO glass).

The charge separation efficiency $\left(\eta_{s e p}\right)$ and the hole transfer efficiency $\left(\eta_{t r}\right)$ were evaluated using the approach reported by Dotan et al., ${ }^{[47]}$ and utilizing sodium sulfite as a readily oxidizable reducing agent. ${ }^{[48]}$ The hole transfer efficiency $\left(\eta_{t r}\right)$ was determined using the equation:

$$
\eta_{t r}=J_{\mathrm{H}_{2} \mathrm{O}} / \mathrm{N}_{\mathrm{Na}_{2} \mathrm{SO}_{3}}
$$

where $J_{\mathrm{H}_{2} \mathrm{O}}$ and $\mathrm{J}_{\mathrm{Na}_{2} \mathrm{SO}_{3}}$ are the photocurrents measured in the absence and presence of additional hole scavenger $\left(\mathrm{Na}_{2} \mathrm{SO}_{3}\right)$, respectively. The charge separation efficiency $\left(\eta_{\text {sep }}\right)$ is estimated by the equation: 


$$
\eta_{\text {sep }}=J_{\mathrm{Na}_{2} \mathrm{SO}_{3}} / J_{\max }
$$

where $J_{\max }$ is the maximal photocurrent obtained by integrating the absorptance spectrum (Figure 1b) over the AM1.5G solar spectrum (ASTM G-173; ${ }^{[49]} 1.5$ sun intensity) from $420 \mathrm{~nm}$ to $600 \mathrm{~nm}$ with absorptance at $600 \mathrm{~nm}$ as a baseline.

The oxygen evolution was recorded by FireSting optical fiber oxygen meter (PyroScience, $\mathrm{GmbH}$ ) in a home-made air-tight two-compartment cell with the oxygen collection efficiency as approximately $75 \%$, which was estimated by a direct electrolysis using a Pt working electrode. The volume of the photoanode compartment was $5 \mathrm{~mL}$. The oxygen concentrations are not corrected for the losses in the gaseous headspace. The electrolyte was purged with argon before the electrodes were illuminated under applied potential of $1.12 \mathrm{~V}$ vs. RHE. The incident monochromatic photon-to-current conversion efficiency (IPCE) was recorded using a photoelectric spectrometer (Instytut Fotonowy Sp. z o.o.) equipped with a tunable monochromatic light source provided with a $150 \mathrm{~W}$ Xenon lamp and a grating monochromator with a bandwidth of $\sim 10 \mathrm{~nm}$. The value of photocurrent density was the difference between current density under irradiation and in the dark in steady-state conditions with a wavelength sampling interval of $10 \mathrm{~nm}$. The IPCE value for each wavelength was calculated according to equation:

$$
\operatorname{IPCE}(\%)=\left(i_{p h} h c\right) /(\lambda P q) \times 100 \%
$$

where $i_{p h}$ is the photocurrent density, $h$ is Planck's constant, $c$ is the velocity of light, $P$ is the light power density, $\lambda$ is the irradiation wavelength, and $q$ is the elementary charge. The electrolyte for all photoelectrochemical measurements was $0.1 \mathrm{M}$ sodium borate electrolyte with $\mathrm{pH}$ value of 8.0. $\mathrm{Na}_{2} \mathrm{SO}_{3}(0.1 \mathrm{M})$ was dissolved in the electrolyte when photocurrents were measured in the presence of sacrificial electron donor. All potentials are recalculated and reported vs. RHE.

\section{Results and discussions}

The immobilization of the negatively charged $\left[\mathrm{CO}_{4}\left(\mathrm{H}_{2} \mathrm{O}\right)_{2}\left(\mathrm{PW}_{9} \mathrm{O}_{34}\right)_{2}\right]^{10-}(\mathrm{CoPOM})$ water oxidation catalyst onto polymeric carbon nitride is challenging since the surface of carbon nitride is known to be negatively charged due to large amount of unprotonated surface Brønsted base moieties that can be protonated only by highly concentrated strong acids. ${ }^{[50,51]}$ In order to effectively immobilize the anionic CoPOM cocatalyst onto the internal surface of our porous $\mathrm{CN}_{x}-\mathrm{TiO}_{2}$ photoelectrodes, we have therefore utilized the layer-by-layer technique demonstrated by Jeon et al. for immobilization of CoPOM onto various metal oxides. ${ }^{[45]}$ The $\mathrm{CN}_{\mathrm{x}}-\mathrm{TiO}_{2}$ electrodes carrying negative surface net charge were sequentially immersed into a solution of the cationic polyethyleneimine (PEI) and a solution of 
the anionic CoPOM for the desired number of times to fabricate the CoPOM-PEI-CN $-\mathrm{CiO}_{2}$ photoanode. It is known that PEI can be protonated in a wide $\mathrm{pH}$ range $(\mathrm{pH} 3-10)$ when dissolved in aqueous solutions. ${ }^{[52]}$ The positively charged cationic $\mathrm{PEI}$ thus plays a role of an electrostatic linker between $\mathrm{CN}_{\mathrm{x}}$ and CoPOM that are both charged negatively. For comparison, the $\mathrm{CN}_{x}-\mathrm{TiO}_{2}$ electrodes were also only dipped into the CoPOM solution resulting in the reference, linker-free electrodes $\mathrm{CoPOM}-\mathrm{CN}_{\mathrm{x}}-\mathrm{TiO}_{2}$. To evaluate and compare the CoPOM loading of the two CoPOM-containing $\mathrm{CN}_{x}-\mathrm{TiO}_{2}$ electrodes, energy dispersive X-ray (EDX) spectra were recorded. The CoPOM-PEI-CN $-\mathrm{TiO}_{2}$ electrode shows significantly higher concentration of elements contained in CoPOM, with 0.35 at\% Co, 0.13 at\% P and 0.97 at\% W, compared to 0.05 at $\% \mathrm{Co}, 0.07$ at\% $\mathrm{P}$ and 0.03 at $\% \mathrm{~W}$ in case of the PEl-free CoPOM-CN $-\mathrm{TiO}_{2}$ reference electrode (Supporting Information, Fig. S1). The higher CoPOM loading of CoPOM-PEI-CN $-\mathrm{TiO}_{2}$ was further corroborated by XPS, showing the increase of surface concentration of Co by the factor of 3.4 in photoelectrodes comprising the PEl linker (Supporting Information, Figure S2). In addition, the EDX mapping (Supporting Information, Fig. S3) depicts the homogeneous distribution of CoPOM within the porous $\mathrm{CN}_{x}-\mathrm{TiO}_{2}$ structure. Finally, only in case of CoPOM-PEI-CN $-\mathrm{CN}_{\mathrm{x}}-\mathrm{TiO}_{2}$, the characteristic IR fingerprint of $\mathrm{COPOM}^{[40]}$ is detectable (Fig. 1a), which confirms improved CoPOM immobilization compared to electrodes without the cationic PEI linker. We conclude that the more effective immobilization of COPOM in the CoPOM-PEI-CN $-\mathrm{CiO}_{2}$ photoanodes is due to beneficial effect of the electrostatic attraction between the positively charged PEI linker and the negatively charged $\mathrm{CN}_{\mathrm{x}}$ and $\mathrm{CoPOM}$ components.

Figure $1 \mathrm{~b}$ depicts the UV-Vis electronic absorption spectra of $\mathrm{TiO}_{2}, \mathrm{CN}_{\mathrm{x}}-\mathrm{TiO}_{2}, \mathrm{CoPOM}-\mathrm{CN}_{\mathrm{x}}-\mathrm{TiO}_{2}$ and CoPOM-PEI-CN $-\mathrm{CiO}_{2}$. All $\mathrm{CN}_{\mathrm{x}}$-containing electrodes exhibit a significant red shift compared to the optical absorption of pristine anatase $\mathrm{TiO}_{2}(3.2 \mathrm{eV}, \sim 390 \mathrm{~nm})$ and $\mathrm{CN}_{\mathrm{x}}(2.9 \mathrm{eV}, \sim 428 \mathrm{~nm})$, which we ascribe to effective sensitization of $\mathrm{TiO}_{2}$ by $\mathrm{CN}_{x}$, including formation of a charge-transfer complex between $\mathrm{CN}_{\mathrm{x}}$ and $\mathrm{TiO}_{2}$, making thus possible also the direct optical electron transfer from the HOMO of $\mathrm{CN}_{\mathrm{x}}$ to the conduction band of $\mathrm{TiO}_{2} \cdot{ }^{[53]}$ The optical absorption edge of the hybrid photoanodes ( $2.6 \mathrm{eV}, \sim 477 \mathrm{~nm}$ ) determined from the Tauc plots (Supporting Information, Fig. S4) is larger than the value typically obtained in our previous studies $(\sim 2.3-2.5 \mathrm{eV}))^{[24,32-38]}$ which can be explained by the inherent limitations of the Tauc formalism as applied for bandgap determination of hybrid materials, ${ }^{[54]}$ and to the fact that in previous studies we determined the bandgap using the Kubelka-Munk function calculated from diffuse reflectance spectra of corresponding powders, while here we use absorptance data obtained from measurements on complete photoanodes. Notably, the change in electronic absorption properties upon the deposition of the CoPOM catalyst is negligible, which indicates that the parasitic light absorption by the CoPOM catalyst is very low. This clearly highlights the advantage of using the molecular CoPOM as compared to, for example, cobalt oxide catalysts that typically show 
significant light absorption in the visible due to their fully developed band structure and correspondingly low bandgap, blocking thus partially the visible light absorption by the light absorber. ${ }^{[33]}$
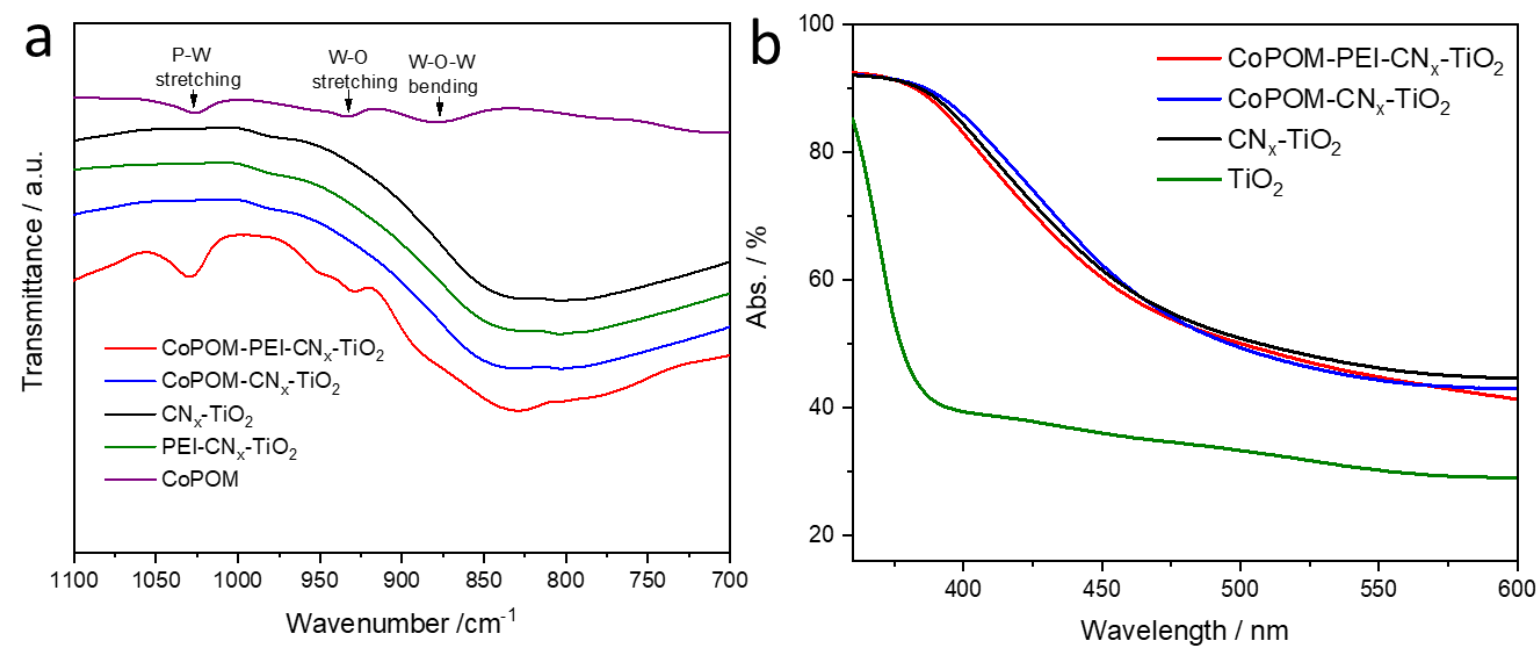

Figure 1: ATR-FTIR spectra of all $\mathrm{CN}_{\mathrm{x}}$-containing electrodes and CoPOM powder (a); UV-Vis electronic absorption spectra of the photoanodes; Abs. = absorptance (b). The non-zero baseline can be ascribed to the differences in internal reflection and scattering at the $\mathrm{FTO} / \mathrm{TiO}_{2}$ interface in the transmittance and reflectance measurements modes. ${ }^{[55]}$

The photoelectrocatalytic properties of our photoanodes were investigated under visible light $(\lambda>$ $420 \mathrm{~nm}$ ) using an appropriate cutoff-filter, in order to effectively shut off the intrinsic UV light absorption of $\mathrm{TiO}_{2}$. The porous $\mathrm{TiO}_{2}$ layer thus serves solely as an electron-collecting scaffold that transports electrons injected under visible light irradiation from $\mathrm{CN}_{\mathrm{x}}$ into $\mathrm{TiO}_{2}$ to the underlying FTO glass support, whereas the oxidizing equivalents (i.e., photoholes) photogenerated in $\mathrm{CN}_{\mathrm{x}}$ should be ideally channeled to the water-oxidizing CoPOM catalyst to drive dioxygen evolution from water. First, potential-dependent photocurrents (Figure 2a) were measured for all electrodes utilizing illumination by chopped visible light $\left(\lambda>420 \mathrm{~nm}, 150 \mathrm{~mW} \mathrm{~cm}^{-2}\right)$ in borate electrolyte (pH 8). As expected, no photocurrents could be detected at the pristine $\mathrm{TiO}_{2}$ substrate since anatase $\mathrm{TiO}_{2}$ cannot be excited by visible light. The photocurrents recorded for the $\mathrm{CN}_{\mathrm{x}}-\mathrm{TiO}_{2}$ electrode without any CoPOM catalyst are attributed to the photocorrosion processes presumably at the $\mathrm{CN}_{\mathrm{x}} / \mathrm{TiO}_{2}$ interface as no oxygen evolution was detected at this electrode under identical experimental conditions (see Figure 4). In contrast, the photocurrent values significantly increased in the presence of both $\mathrm{CN}_{\mathrm{x}}$ sensitizer and CoPOM cocatalyst. Importantly, the polymeric PEI linker-containing CoPOM-PEI-CN ${ }_{x}-\mathrm{TiO}_{2}$ photoanode showed the highest photocurrents within the whole potential range and also the highest monochromatic quantum efficiencies (IPCE) measured at a constant bias potential of $1.12 \mathrm{~V} v \mathrm{vs}$. RHE (Figure 2d). Importantly, the CoPOM-PEI- $\mathrm{CN}_{\mathrm{x}}-\mathrm{TiO}_{2}$ photoanode exhibited also the most negative photocurrent onset potential of $0.2 \mathrm{~V}$ vs. RHE, which clearly indicates an improved rectifying behavior due to more effective extraction of photogenerated holes from $\mathrm{CN}_{\mathrm{x}}$. Figure $2 \mathrm{~b}$ shows photocurrent 
transients under the same visible light irradiation conditions at a constant potential of $0.78 \mathrm{~V} v s$. RHE, and indicates a relatively good short-term stability of the photocurrent response. Interestingly, for the CoPOM-free electrode (black line), the current spikes after switching on the light and negative current overshoots appearing after the light is switched off become significantly more pronounced. Such spikes and overshoots are a typical fingerprint of intense surface recombination processes, ${ }^{[56]}$ indicating that, in the absence of water oxidation catalyst, the photoholes in $\mathrm{CN}_{\mathrm{x}}$ do not undergo the desired interfacial transfer, but instead accumulate in the $\mathrm{CN}_{\mathrm{x}}$ layer and subsequently either recombine or induce photocorrosion. In contrast, the current spikes are less pronounced and the overshoots are nearly absent in both CoPOM-containing electrodes, which again indicates that the CoPOM cocatalyst can extract holes generated in the $\mathrm{CN}_{\mathrm{x}}$ layer and trigger the desired water oxidation reaction.

In order to shed more light on the factors governing the photoresponse of CoPOM-containing photoanodes, we performed an analysis of charge separation $\left(\eta_{\text {sep }}\right)$ and hole transfer $\left(\eta_{t r}\right)$ efficiencies according to established protocols. ${ }^{[47,48,57]}$ This analysis is based on the assumption that the measured photocurrent density in water oxidation can be calculated by multiplying the maximum possible photocurrent (obtained from the absorbed photon flux) by $\eta_{\text {sep }}$ and $\eta_{t r}$, whereby the hole transfer efficiency $\eta_{t r}$ in the presence of a readily oxidizable reducing agent (here $\mathrm{Na}_{2} \mathrm{SO}_{3}$ ) is taken as $100 \%$; for details see the experimental section. The calculated $\eta_{t r}$ and $\eta_{\text {sep }}$ values for the both CoPOM-containing electrode are depicted in Figure 2c, calculated from data in Figures 2a and S5. As expected, both efficiencies show clear dependence on the applied potential as stronger positive applied bias is beneficial for both charge separation and hole transfer. Notably, the charge separation efficiency $\eta_{\text {sep }}$ is very similar for both PEI linker-free CoPOM-CN $-\mathrm{CiO}_{2}$ and PEI-containing CoPOM-PEI-CN $-\mathrm{CTO}_{2}$, which is also in line with only minor differences in photoluminescence spectra of the corresponding photoanodes that are possibly related to slightly more efficient quenching of emissive states in $\mathrm{CN}_{\mathrm{x}}$ (Supporting Information, Figure S6). In stark contrast, the CoPOM-PEI-CN $-\mathrm{TiO}_{2}$ exhibits significantly higher charge transfer efficiencies than $\mathrm{CoPOM}-\mathrm{CN}_{\mathrm{x}}-\mathrm{TiO}_{2}$ in the whole potential range. In other words, this data suggests that the superior photoelectrocatalytic behavior of the PEI linker-containing CoPOM-PEI-CN $-\mathrm{CN}_{\mathrm{x}}-\mathrm{TiO}_{2}$ photoanode arises from a more efficient transfer of photogenerated holes from $\mathrm{CN}_{\mathrm{x}}$ to water, which can be attributed to the higher CoPOM loading due to the beneficial effect of the cationic PEl polymer linker. 

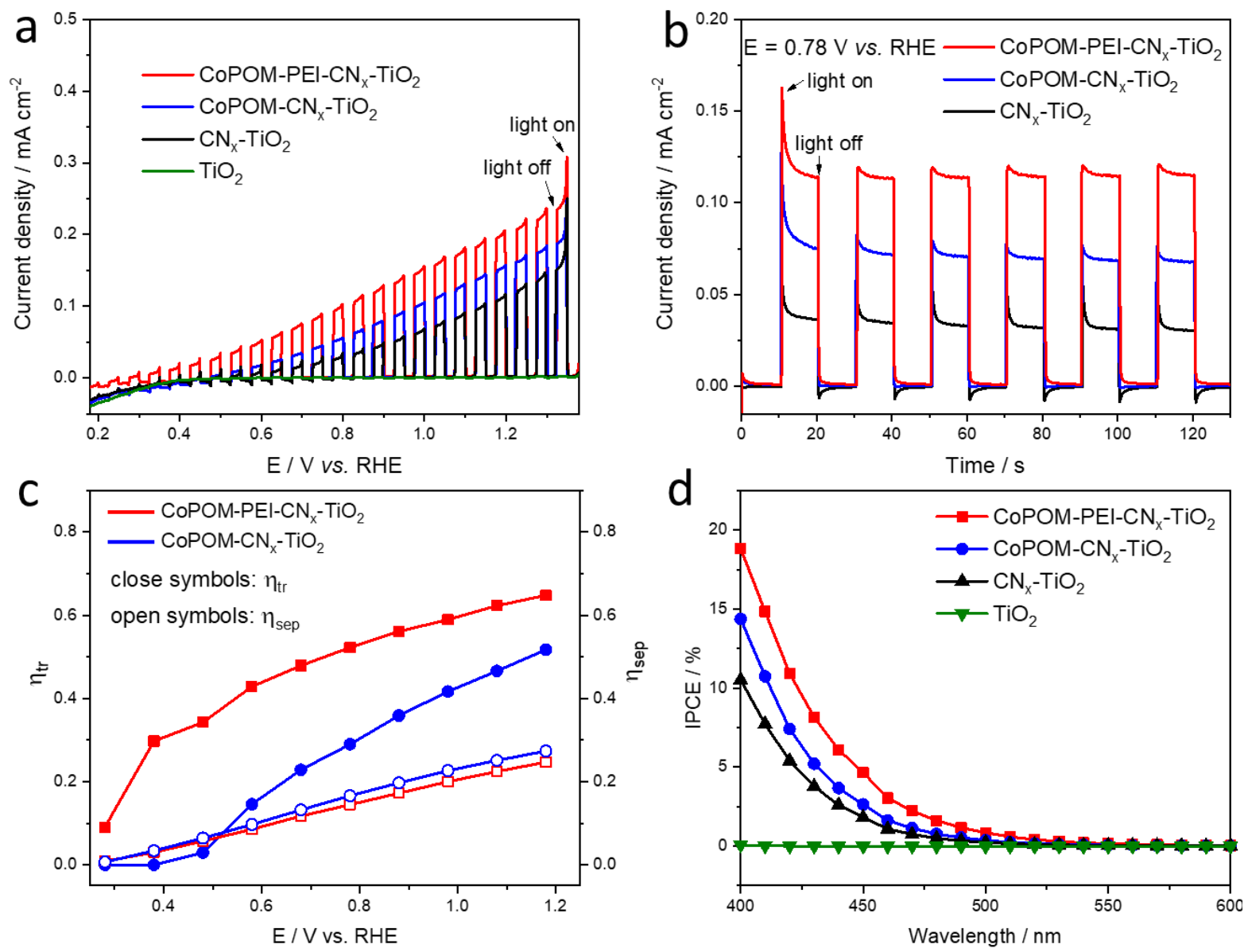

Figure 2: Photocurrents recorded under intermittent polychromatic visible light $(\lambda>420 \mathrm{~nm})$ in borate electrolyte $(0.1 \mathrm{M}, \mathrm{pH}$ 8.0) at cathodic sweep of $5 \mathrm{mV} \mathrm{s}^{-1}$ (a); photocurrent transients recorded under intermittent polychromatic visible light $(\lambda>$ $\left.420 \mathrm{~nm}, 150 \mathrm{~mW} / \mathrm{cm}^{2}\right)$ in borate electrolyte $(0.1 \mathrm{M}, \mathrm{pH} 8.0)$ at $0.78 \mathrm{~V}$ vs. RHE (b); hole transfer efficiency $\left(\eta_{\mathrm{tr}}\right)$ and charge separation efficiency $\left(\eta_{\text {sep }}\right)$ of CoPOM-containing electrodes under different applied potentials (c); IPCE spectra under intermittent monochromatic irradiation measured at $1.12 \mathrm{~V} v$ s. RHE in borate electrolyte $(0.1 \mathrm{M}, \mathrm{pH} 8.0)(\mathrm{d})$.

However, in addition to its beneficial effect on the CoPOM immobilization, a question arises whether the cationic PEI polymer could potentially also act as a sacrificial electron donor that can be simply more easily oxidized than water by holes from $\mathrm{CN}_{\mathrm{x}}$. In order to address directly this issue, we measured the photocurrents from the $\mathrm{CN}_{x}-\mathrm{TiO}_{2}$ electrode modified with PEI polymer only (dipped in PEI solution 5 times), and the measurements at $\mathrm{PEI}-\mathrm{CN}_{\mathrm{x}}-\mathrm{TiO}_{2}$ photoanodes were repeated subsequently in four cycles. The deposition of PEI enhanced photocurrents, but a gradual decrease of photocurrents was observed, ending up at the same values as those for the $\mathrm{CN}_{x}-\mathrm{TiO}_{2}$ photoanode (Figure 3a). Hence, in the absence of the CoPOM catalyst, the PEI does extract effectively the holes from $\mathrm{CN}_{\mathrm{x}}$, but is thereby oxidatively degraded. As a next step, the same protocol was also applied to the CoPOM-PEI-CN $-\mathrm{TiO}_{2}$ photoanode. Contrary to the gradual decline of photocurrents observed for $\mathrm{PEI}-\mathrm{CN}_{\mathrm{x}}-\mathrm{TiO}_{2}$, the photocurrents at COPOM-PEI-CN $-\mathrm{TiO}_{2}$ remain completely stable over all four cycles (Figure $3 \mathrm{~b}$ ). This 
is also in line with the chronoamperometric photocurrent measurements of the three electrodes (Figure 3c), which show that $\mathrm{PEI}-\mathrm{CN}_{\mathrm{x}}-\mathrm{TiO}_{2}$ exhibits a fast decline of photocurrent due to degradation of $\mathrm{PEl}$ in the absence of COPOM, whereby the photocurrent at COPOM-PEI-CN $-\mathrm{TiO}_{2}$ is practically stable. Therefore, we conclude that in the presence of COPOM, the holes are efficiently transferred from PEI to the COPOM catalyst where they drive water oxidation, and the cationic PEI linker is thereby effectively stabilized.
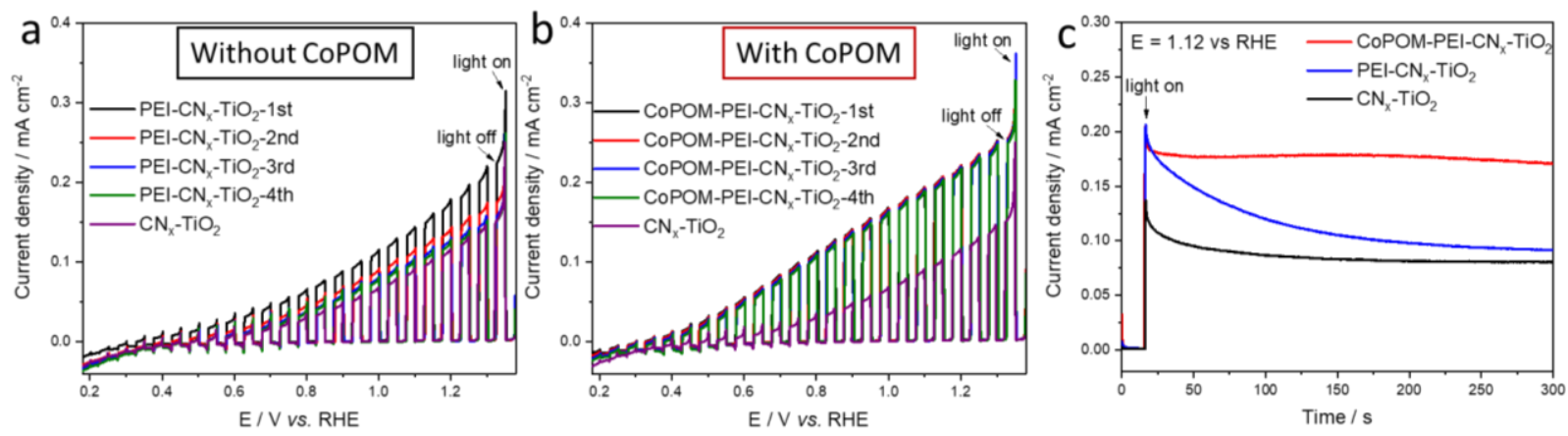

Figure 3: Photocurrent stability test recorded under intermittent polychromatic irradiation $\left(\lambda>420 \mathrm{~nm}, 150 \mathrm{~mW} / \mathrm{cm}^{2}\right)$ in a borate electrolyte $\left(0.1 \mathrm{M}, \mathrm{pH}\right.$ 8) at cathodic sweep of $5 \mathrm{mV} \mathrm{s}^{-1}$ for photoanode with (a) and without (b) the CoPOM cocatalyst; chronoamperometric curves under illumination showing the degradation of PEI in the absence of CoPOM (c).

In order to unambiguously prove the dioxygen evolution at CoPOM modified photoanodes, we performed photoelectrocatalytic OER measurements (Figure 4a) in a borate solution $(\mathrm{pH} 8)$ under prolonged (1 hour) visible light irradiation $\left(\lambda>420 \mathrm{~nm}, 150 \mathrm{~mW} / \mathrm{cm}^{2}\right)$. Both CoPOM-containing hybrid photoanodes, COPOM-CN $-\mathrm{TiO}_{2}$ and CoPOM-PEI-CN $-\mathrm{CNO}_{2}$, clearly exhibit OER activity under visible light illumination. This confirms our assumption that charge transfer from $\mathrm{CN}_{\mathrm{x}}$ to $\mathrm{CoPOM}$ is feasible and that the presence of the COPOM cocatalyst is necessary to trigger the OER. Importantly, at the PEl-containing electrode the oxygen evolution rate was doubled compared to the counterpart photoanode without PEI. Importantly, no oxygen evolution was observed at the CoPOM-free $\mathrm{CN}_{\mathrm{x}}-\mathrm{TiO}_{2}$ photoanode despite substantial photocurrents that can be ascribed to photocorrosion. ${ }^{[36]}$ This result is also in line with our previous studies that confirmed that the presence of an effective OER catalyst is absolutely necessary to observe oxygen as a product of water oxidation at $\mathrm{CN}_{x}-\mathrm{TiO}_{2}$ hybrid photoanodes. ${ }^{[24,32-39]}$ On the other hand, $\mathrm{CN}_{\mathrm{x}}$-free pristine $\mathrm{TiO}_{2}$ photoanodes modified with $\mathrm{CoPOM}$ exhibited neither photocurrents nor oxygen evolution since pristine $\mathrm{TiO}_{2}$ does not absorb in the visible range. The apparent (based on dissolved $\mathrm{O}_{2}$ and uncorrected for losses in the headspace) Faradaic efficiencies (FE) of oxygen evolution for CoPOM-PEI-CN $-\mathrm{CNiO}_{2}(15 \% \pm 4 \%)$ and for CoPOM-CN $-\mathrm{TiO}_{2}(12 \%$ $\pm 4 \%$ ) are rather low, which suggest that even in the best photoanodes the overall utilization of holes generated in $\mathrm{CN}_{\mathrm{x}}$ for water oxidation is still far from optimum, and a substantial portion of holes does not induce the OER but instead contributes to the photocorrosion of $\mathrm{CN}_{\mathrm{x}}$. The improved photocurrent onset potential, higher oxygen production rate and $\mathrm{FE}$ at the PEI-containing CoPOM-PEI-CN $-\mathrm{TiO}_{2}$ 
photoanode clearly confirm the beneficial effect of the cationic PEI polymer that serves as an effective linker by establishing the electrostatic attraction between the $\mathrm{CN}_{\mathrm{x}}$ sensitizer and CoPOM catalyst that are both negatively charged. This results in a more efficient hole extraction from $\mathrm{CN}_{\mathrm{x}}$ and more effective utilization of photogenerated holes for water oxidation due to the more effective immobilization (i.e., higher loading) of the CoPOM water oxidation catalyst.
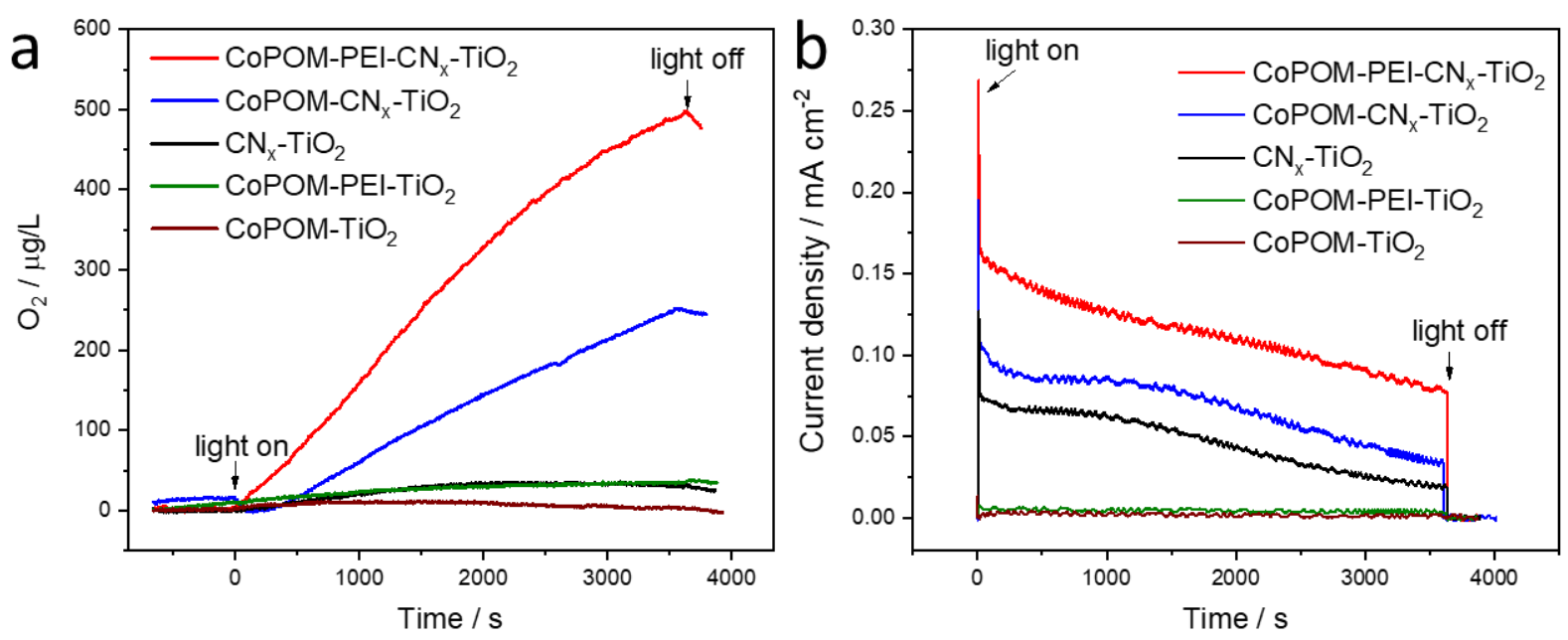

Figure 4: Dioxygen evolution (a) and corresponding photocurrent transients (b); measured under polychromatic visible light irradiation $\left(\lambda>420 \mathrm{~nm}, 150 \mathrm{~mW} / \mathrm{cm}^{2}\right)$ at $1.12 \mathrm{~V} v$ s. RHE in a borate electrolyte $(0.1 \mathrm{M}, \mathrm{pH} 8.0)$. The oxygen evolution was measured at least at three different electrodes (representative curves are shown), and the error is taken as $2 \sigma(\sigma=$ standard deviation; $95 \%$ confidence interval).

\section{Conclusion}

A triad photoanode comprising a molecular cobalt polyoxometalate (CoPOM) embedded in the porous structure of hybrid photoanodes consisting of polymeric carbon nitride deposited onto an electron collecting porous $\mathrm{TiO}_{2}$ layer is reported for the first time. The photoanodes exhibit complete water oxidation to dioxygen under visible $(\lambda>420 \mathrm{~nm})$ light irradiation, with photocurrents down to relatively low bias potentials of $0.2 \mathrm{~V}$ vs. RHE. Importantly, it is demonstrated that polyethyleneimine (PEI), a positively charged cationic polymer that has been previously reported to enable improved deposition of CoPOM onto various metal oxides, ${ }^{[45,46][58]}$ can also act as a highly effective electrostatic linker for immobilization of the anionic CoPOM onto the negatively charged surface of carbon nitride. Mechanistic studies revealed that the optimized deposition of COPOM using the PEI linker translates directly into improved efficiency of the transfer of photogenerated oxidizing equivalents (holes) to water molecules and thus to enhanced oxygen evolution. On the other hand, the charge separation efficiency in triad photoanodes was largely unaffected by the CoPOM loading, and remained rather low (below $10 \%$ at moderate bias potentials), suggesting that primary recombination is a key performance bottleneck in triad photoanodes. Importantly, we also show that the PEI linker is effectively stabilized in the presence of the COPOM catalyst that efficiently extracts the holes from PEI, 
preventing thus its oxidative degradation that takes place in the absence of CoPOM. This work thus highlights the importance of careful design of multi-component photoelectrocatalytic systems, and provides a simple protocol for effective immobilization of POM-based catalysts into soft matter-based photoelectrocatalytic architectures for light-driven water oxidation.

\section{Acknowledgements}

This work was funded by the Deutsche Forschungsgemeinschaft (DFG, German Research Foundation) - Project number 364549901-TRR 234 CataLight (Projects B6, B2, C4). The authors thank Joachim Bansmann for his help with XPS analysis. RG and SR acknowledge the financial support from the Vector Stiftung.

\section{Conflict of interest:}

There is no conflict of interest to declare.

\section{References}

[1] T. Hisatomi, J. Kubota, K. Domen, Chem. Soc. Rev. 2014, 43, 7520.

[2] Y. Wang, H. Suzuki, J. Xie, O. Tomita, D. J. Martin, M. Higashi, D. Kong, R. Abe, J. Tang, Chem. Rev. 2018, 118, 5201.

[3] S. Chen, T. Takata, K. Domen, Nat. Rev. Mater. 2017, 2, 17050.

[4] X. Li, J. Yu, J. Low, Y. Fang, J. Xiao, X. Chen, J. Mater. Chem. A 2015, 3, 2485.

[5] S. J. A. Moniz, S. A. Shevlin, D. J. Martin, Z. X. Guo, J. Tang, Energy Environ. Sci. 2015, 8, 731.

[6] X. Wang, K. Maeda, A. Thomas, K. Takanabe, G. Xin, J. M. Carlsson, K. Domen, M. Antonietti, Nat. Mater. 2009, 8, 76.

[7] F. K. Kessler, Y. Zheng, D. Schwarz, C. Merschjann, W. Schnick, X. Wang, M. J. Bojdys, Nat. Rev. Mater. 2017, 2, 1.

[8] D. J. Martin, P. J. T. Reardon, S. J. A. Moniz, J. Tang, J. Am. Chem. Soc. 2014, 136, 12568.

[9] D. J. Martin, K. Qiu, S. A. Shevlin, A. D. Handoko, X. Chen, Z. Guo, J. Tang, Angew. Chemie Int. Ed. 2014, 53, 9240.

[10] G. Liu, T. Wang, H. Zhang, X. Meng, D. Hao, K. Chang, P. Li, T. Kako, J. Ye, Angew. Chemie 
2015, 127, 13765.

[11] M. Zhu, S. Kim, L. Mao, M. Fujitsuka, J. Zhang, X. Wang, T. Majima, J. Am. Chem. Soc. 2017, 139, 13234.

[12] A. Rajagopal, E. Akbarzadeh, C. Li, D. Mitoraj, I. Krivtsov, C. Adler, T. Diemant, J. Biskupek, U. Kaiser, C. Im, M. Heiland, T. Jacob, C. Streb, B. Dietzek, R. Beranek, Sustain. Energy Fuels 2020, 4, 6085.

[13] G. Gao, Y. Jiao, E. R. Waclawik, A. Du, J. Am. Chem. Soc. 2016, 138, 6292.

[14] G. Zhao, H. Pang, G. Liu, P. Li, H. Liu, H. Zhang, L. Shi, J. Ye, Appl. Catal. B Environ. 2017, 200, 141.

[15] Y. Shiraishi, S. Kanazawa, Y. Sugano, D. Tsukamoto, H. Sakamoto, S. Ichikawa, T. Hirai, ACS Catal. 2014, 4, 774.

[16] A. Savateev, I. Ghosh, B. König, M. Antonietti, Angew. Chemie - Int. Ed. 2018, 57, 15936.

[17] I. Ghosh, J. Khamrai, A. Savateev, N. Shlapakov, M. Antonietti, B. König, Science (80-. ). 2019, 365,360 .

[18] I. Krivtsov, D. Mitoraj, C. Adler, M. Ilkaeva, M. Sardo, L. Mafra, C. Neumann, A. Turchanin, C. Li, B. Dietzek, R. Leiter, J. Biskupek, U. Kaiser, C. Im, B. Kirchhoff, T. Jacob, R. Beranek, Angew. Chemie - Int. Ed. 2020, 59, 487.

[19] M. Wei, L. Gao, J. Li, J. Fang, W. Cai, X. Li, A. Xu, J. Hazard. Mater. 2016, 316, 60.

[20] C. Zhou, G. Zeng, D. Huang, Y. Luo, M. Cheng, Y. Liu, W. Xiong, Y. Yang, B. Song, W. Wang, J. Hazard. Mater. 2020, 386, 121947.

[21] J. T. Kirner, R. G. Finke, J. Mater. Chem. A 2017, 5, 19560.

[22] M. N. Collomb, D. V. Morales, C. N. Astudillo, B. Dautreppe, J. Fortage, Sustain. Energy Fuels 2019, 4, 31.

[23] D. G. Nocera, Acc. Chem. Res. 2017, 50, 616.

[24] L. Wang, D. Mitoraj, S. Turner, O. V. Khavryuchenko, T. Jacob, R. K. Hocking, R. Beranek, ACS Catal. 2017, 7, 4759.

[25] C. Adler, I. Krivtsov, D. Mitoraj, L. dos Santos-Gómez, S. García-Granda, C. Neumann, J. Kund, C. Kranz, B. Mizaikoff, A. Turchanin, R. Beranek, ChemSusChem 2021, 14, 2170. 
[26] C. Adler, S. Selim, I. Krivtsov, C. Li, D. Mitoraj, B. Dietzek, J. R. Durrant, R. Beranek, Adv. Funct. Mater. 2021, 31, 2105369.

[27] H. Ou, P. Yang, L. Lin, M. Anpo, X. Wang, Angew. Chemie - Int. Ed. 2017, 56, 10905.

[28] F. Podjaski, J. Kröger, B. V. Lotsch, Adv. Mater. 2018, 30, 1705477.

[29] J. Qin, J. Barrio, G. Peng, J. Tzadikov, L. Abisdris, M. Volokh, M. Shalom, Nat. Commun. 2020, $11,1$.

[30] N. Karjule, J. Barrio, L. Xing, M. Volokh, M. Shalom, Nano Lett. 2020, 20, 4618.

[31] M. Shalom, S. Gimenez, F. Schipper, I. Herraiz-Cardona, J. Bisquert, M. Antonietti, Angew. Chemie 2014, 126, 3728.

[32] L. Wang, M. Bledowski, A. Ramakrishnan, D. König, A. Ludwig, R. Beranek, J. Electrochem. Soc. 2012, 159, H616.

[33] M. Bledowski, L. Wang, A. Ramakrishnan, A. Bétard, O. V. Khavryuchenko, R. Beranek, ChemPhysChem 2012, 13, 3018.

[34] M. Bledowski, L. Wang, A. Ramakrishnan, R. Beranek, J. Mater. Res. 2013, 28, 411.

[35] B. Mei, H. Byford, M. Bledowski, L. Wang, J. Strunk, M. Muhler, R. Beranek, Sol. Energy Mater. Sol. Cells 2013, 117, 48.

[36] M. Bledowski, L. Wang, S. Neubert, D. Mitoraj, R. Beranek, J. Phys. Chem. C 2014, 118, 18951.

[37] O. V. Khavryuchenko, L. Wang, D. Mitoraj, G. H. Peslherbe, R. Beranek, J. Coord. Chem. 2015, $68,3317$.

[38] P. Longchin, D. Mitoraj, O. M. Reyes, C. Adler, N. Wetchakun, R. Beranek, JPhys Energy 2020, 2, 44001 .

[39] R. Gong, D. Mitoraj, R. Leiter, M. Mundszinger, A. K. Mengele, I. Krivtsov, J. Biskupek, U. Kaiser, R. Beranek, S. Rau, Front. Chem. 2021, 9, 1.

[40] Q. Yin, J. M. Tan, C. Besson, Y. V Geletii, D. G. Musaev, A. E. Kuznetsov, Z. Luo, K. I. Hardcastle, C. L. Hill, Science (80-. ). 2010, 328, 342.

[41] M. Natali, S. Berardi, A. Sartorel, M. Bonchio, S. Campagna, F. Scandola, Chem. Commun. $2012,48,8808$.

[42] J. W. Vickers, H. Lv, J. M. Sumliner, G. Zhu, Z. Luo, D. G. Musaev, Y. V Geletii, C. L. Hill, J. Am. 
Chem. Soc. 2013, 135, 14110.

[43] J. J. Stracke, R. G. Finke, ACS Catal. 2013, 3, 1209.

[44] J. J. Stracke, R. G. Finke, ACS Catal. 2014, 4, 79.

[45] D. Jeon, H. Kim, C. Lee, Y. Han, M. Gu, B. S. Kim, J. Ryu, ACS Appl. Mater. Interfaces 2017, 9, 40151.

[46] Y. Han, K. Choi, H. Oh, C. Kim, D. Jeon, C. Lee, J. H. Lee, J. Ryu, J. Catal. 2018, 367, 212.

[47] H. Dotan, K. Sivula, M. Grätzel, A. Rothschild, S. C. Warren, Energy Environ. Sci. 2011, 4, 958.

[48] Y. Gao, T. W. Hamann, Chem. Commun. 2017, 53, 1285.

[49] (ASTM) G-173 spectra, https://www.nrel.gov/grid/solar-resource/spectra-am1.5.html.

[50] Y. Zhang, A. Thomas, M. Antonietti, X. Wang, J. Am. Chem. Soc. 2009, 131, 50.

[51] F. Guo, Y. Hou, A. M. Asiri, X. Wang, Chem. Commun. 2017, 53, 13221.

[52] R. Mészáros, L. Thompson, M. Bos, P. De Groot, Langmuir 2002, 18, 6164.

[53] M. Bledowski, L. Wang, A. Ramakrishnan, O. V. Khavryuchenko, V. D. Khavryuchenko, P. C. Ricci, J. Strunk, T. Cremer, C. Kolbeck, R. Beranek, Phys. Chem. Chem. Phys. 2011, 13, 21511.

[54] P. Makuła, M. Pacia, W. Macyk, J. Phys. Chem. Lett. 2018, 9, 6814.

[55] I. S. Cho, Z. Chen, A. J. Forman, D. R. Kim, P. M. Rao, T. F. Jaramillo, X. Zheng, Nano Lett. 2011, $11,4978$.

[56] L. M. Peter, Chem. Rev. 1990, 90, 753.

[57] F. F. Abdi, A. Chemseddine, S. P. Berglund, R. Van De Krol, J. Phys. Chem. C 2017, 121, 153.

[58] R. Gong, D. Gao, R. Liu, D. Sorsche, J. Biskupek, U. Kaiser, S. Rau, C. Streb, ACS Appl. Energy Mater. 2021. 


\section{Graphical Abstract}

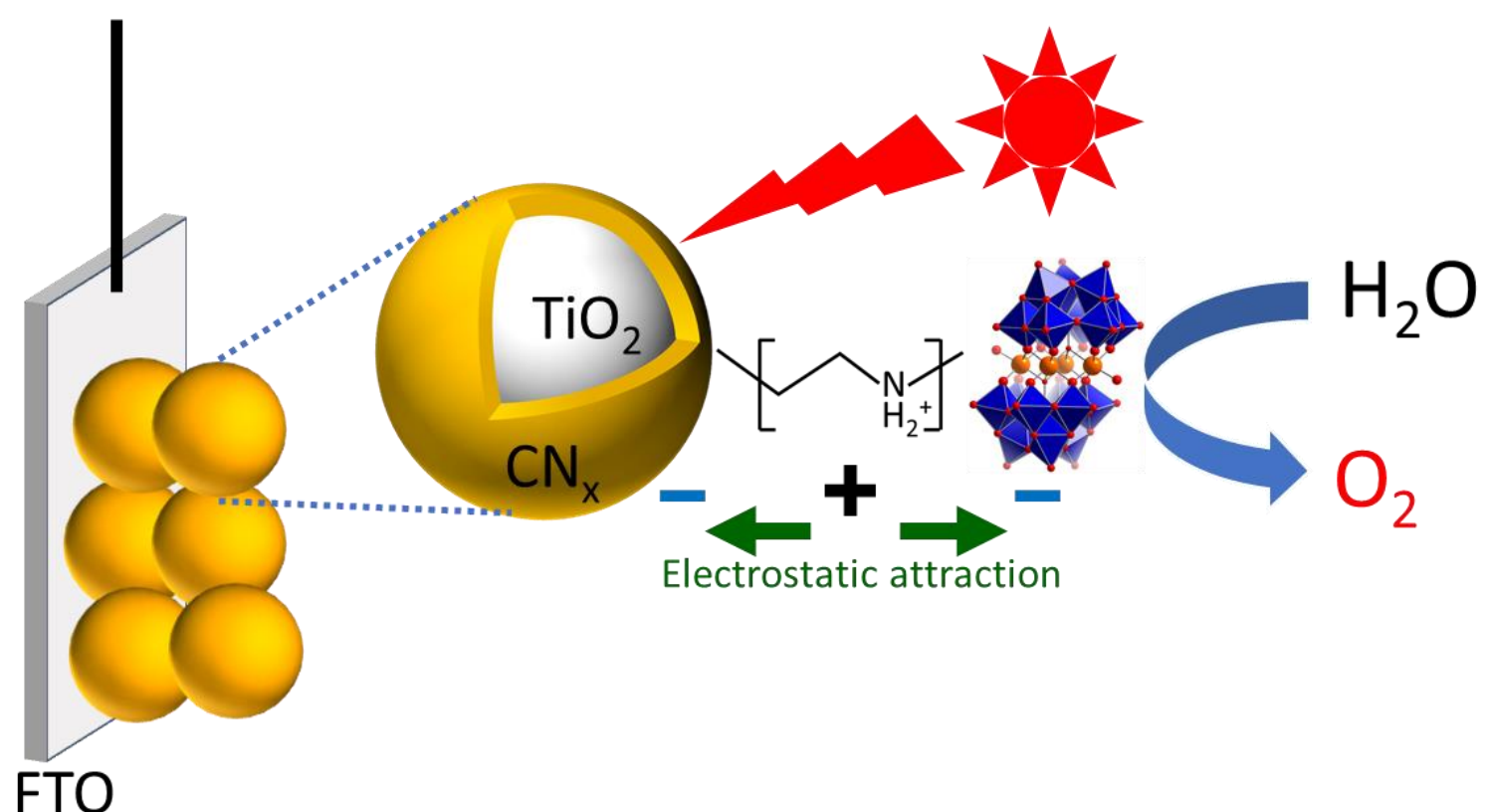

A triadic photoanode comprising a porous $\mathrm{TiO}_{2}$ electron collector scaffold sensitized by polymeric carbon nitride coupled to a molecular cobalt polyoxometalate (CoPOM) catalyst exhibits visible $(\lambda>420 \mathrm{~nm})$ light-driven water oxidation to dioxygen. The beneficial role of cationic polyethyleneimine polymer as an effective electrostatic linker for immobilization of CoPOM onto carbon nitride is highlighted. 